\title{
O que pode a enunciação dizer sobre a reformulação de liuros, desde um ponto de vista benvenistiano?
}

Adriana Pozzani de LA VIELLE *

Universidade Federal do Rio Grande do Sul

Resumo: A teoria enunciativa de Émile Benveniste serve como base para uma breve reflexão acerca da reformulação de livros, reformulação esta que engendra a chamada "edição revista", cuja identidade geralmente costuma ser marcada pela polêmica mesmo/ outro livro. Trata-se, pois, de abordar a relação entre o processo de teorização, de um lado, e, de outro, o sujeito que enuncia o saber, e isso a fim de discutir, por exemplo, a ressignificação de determinadas categorias conceituais e a irrepetível construção do valor referencial de cada enunciado.

Palavras-chave: Ciência; Sentido; Edição revista.

Abstract: Émile Benveniste's theory is the base for a brief discussion about the reformulation of books, reformulation which engenders the so called "revised edition", whose identity has commonly been marked by a controversy between same/other book. We intend to approach the relation between theorization process, on the one hand, and, on the other hand, the subject who enunciates the knowledge, and we do that in order to discuss, for example, the ressignification of some conceptual categories and

\footnotetext{
* Mestre em Estudos da Linguagem pela Universidade Federal do Rio Grande do Sul (UFRGS). Integra o Grupo de Pesquisa em Análises Textuais e Discursivas (UFRGS) e desenvolve pesquisas no campo teórico da Análise do Discurso Francesa. Contato: adriana.vielle@yahoo.com.br.
} 
the unrepeatable construction of the referential value of each énoncé. Key-words: Science; Meaning; Revised edition.

\section{Introdução}

A reformulação de livros foi tema de minha Dissertação de Mestrado em Estudos da Linguagem (PPG-Letras/UFRGS), Pesquisa essa intitulada "Entretextualidade nas fronteiras do enunciável: um olhar sobre o processo discursivo de reformulação de livros" e defendida em 6 de janeiro de 2009. No presente artigo, proponho-me abordar breve e especificamente o estatuto que se pode conferir à edição revista se se assumir um ponto de vista teórico pautado pelas reflexões de Émile Benveniste.

Em Linguística da Enunciação, defende-se que as categorias de pessoa-espaço-tempo (eu-aqui-agora) são constitutivas da língua, e que esta não pode ser pensada fora do uso que dela faz o locutor. Admitido isso, as questões norteadoras deste trabalho são: tomando-se a teoria de Émile Benveniste (tal como ela se constrói a partir da coletânea de artigos presente nos dois tomos dos Problemas de Lingüistica Geral), o que é possível derivar das reflexões do autor para pensar a reformulação de livros, ou seja, este processo que engendra a chamada "edição revista" (ou, eventualmente, "revista e ampliada")? Qual o estatuto que se pode conferir a esse tipo de edição, uma vez considerada a polêmica entre ser o mesmo livro e ser um outro? Interessa-nos, para tanto, examinar as ressignificações, bem como a relação entre o sujeito e as distintas edições de seu livro (relação esta expressa, geralmente, por meio de Nota ou, conforme o caso, de Prefácio). Trata-se de questionar as relações estabelecidas via enunciação entre o locutor e seu ato enunciativo anterior, especialmente no que tange ao jogo entre (ir)repetibilidade e temporalidade, e fazê-lo por meio de um método comparativo (justificável ao permitir localizar, em diacronia, pontos linguisticamente analisáveis de ruptura na enunciação), a fim de identificar e descrever marcas linguísticas que permitem observar os modos como se efetiva, pela enunciação, a irrepetível construção 
do valor referencial do enunciado, e por aí, a emergência do sujeito e a relação deste com o dizer.

O leitor há de solicitar, com muita razão, que nos justifiquemos quanto ao privilégio concedido às reflexões de Émile Benveniste. Adiantemos sucintamente os motivos que nos levam a preferir este linguista; elegemos Benveniste em virtude: a) da definição que o autor propõe ao objeto teórico enunciação; b) da concepção de um aparelho formal da enunciação; c) de seu prisma teórico impor a consideração da tríade eu-aqui-agora, a irrepetibilidade da cena enunciativa (logo, a irrepetibilidade absoluta do sentido), a "trindade natural" (TEIXEIRA, 2004b) imanente ao ato de falar (eu-tu-ele). Consagrado por abordar os modos pelos quais o homem faz-se presente na língua, Benveniste considera que esta, ainda que alguém a fabrique sozinho, só existe se houver, no mínimo, dois falantes que a possam usar como nativos. Uma língua é um consenso coletivo, ponte entre o homem e o mundo. Ao falar, o homem irrepetivelmente "reinventa" a cada instante a língua: cada ato enunciativo é único, e mesmo dizer "bom dia" diariamente a alguém implica reinvenção, uma vez que são sempre irrepetíveis as condições de pessoa-espaço-tempo.

No âmbito do que será discutido aqui, defende-se, portanto, que a teorização enquanto um ato enunciativo permite ver o modo singular de o sujeito relacionar-se com a língua, língua esta da qual esse sujeito, evidentemente, se vale para (re)construir os saberes do campo de conhecimentos ao qual se encontra filiado. Vemos o processo de reformulação (do qual decorrem as edições revistas) enquanto fato linguístico e cremos que analisar tal processo (objeto desta investigação) conforme a perspectiva apontada por Benveniste $(2005 ; 2006)$ significa posicionar-se teoricamente para, em verdade, refletir duplamente sobre a língua: tomando-a, ao mesmo tempo, como sistema combinatório de signos e como exercício da linguagem, sem perder de vista que interessa propriamente não o dito em si, mas o fato de o locutor tê-lo enunciado e o sentido daí decorrente. Adotamos, pois, uma postura teórica que, primando por abordar o sentido na situação da língua em uso, converge para o domínio da Linguística da Enunciação tal como o concebem Flores e Teixeira (2005). 
Resta agora apresentar a forma de estruturação deste trabalho: 1) em um primeiro momento, será feito um recorte de alguns pontos essenciais da teoria benvenistiana; 2) em seguida, serão observados fragmentos extraídos dos pares de edições mobilizados para a presente reflexão; 3) finalmente, será pensado o estatuto da edição revista, especificamente, o que encaminhará à conclusão deste texto.

Metodologicamente, serão adotadas algumas notações, a saber: E1 para a edição "de partida" (neste caso, a edição que é objeto de reformulação); e E2 para a edição revista. Já S1 referirá a situação enunciativa de E1, enquanto S2 o fará quanto à de E2. Para o caso de enunciados existentes apenas na edição revista, e não naquela que é objeto de reformulação, será colocado o símbolo $\varnothing$ no lugar referente ao enunciado de E1, indicando-se, assim, a impossibilidade de efetiva comparação.

\section{Um retorno ao linguista Émile Benveniste: a presença do homem na língua}

Dada a natureza deste escrito, qual seja, a de artigo, focalizaremos apenas alguns trabalhos do autor, organizando-os em torno de dois pilares - a (inter)subjetividade e o aparelho formal da enunciação - aos quais entrelaçaremos temas como a categoria de pessoa, a relação forma-sentido, a singular presença do homem na língua. Hoje temos seus artigos em sincronia (dispõem-se eles ali, lado a lado), porém, deve ser lembrado que foram feitos em diacronia. $\mathrm{E}$ isto não significa que os textos se invalidem uns aos outros; ao contrário: mostram o percurso de elaboração de uma teoria a qual Benveniste nunca fez questão de designar explicitamente como tal, mas que se pode perfeitamente derivar do conjunto de sua obra (lembremos os dois volumes de O Vocabulário das Instituiçoes Indo-européias, nos quais também são colocadas questões semânticas fundamentais).

Linguista referencial ao abordar, a partir do quadro saussuriano, a língua por um prisma que considera a enunciação, Émile Benveniste emerge no auge do formalismo estrutural 
hjelmsleviano e, apesar de também ser estruturalista, propõe uma perspectiva indicial: aquela que, segundo Dahlet (1997, p. 70), estuda "o ato de inserção do sujeito falante na língua". Trata-se aí de um posicionamento epistemológico: Benveniste acredita na indissociabilidade entre homem e linguagem, já que esta integra a natureza daquele. "Única é a condição do homem na linguagem", enuncia este autor em seu artigo "Da subjetividade na linguagem", no qual aborda a presença do homem na língua (2005, p. 287). Ao defender esse posicionamento e situar-se entre continuar/ ultrapassar Saussure (NORMAND, 1996), Benveniste opõe-se a outros pós-saussurianos de seu tempo: no interior de um contexto histórico em que se pregava imanência em Linguística, ${ }^{1}$ ele inova ao acreditar na urgência de um trabalho teórico-analítico que pressuponha o entrelaçamento (pela enunciação) de sujeito, sentido, estrutura, situação. É clara, como aponta Culioli (1999), a revolução benvenistiana no interior da Linguística, em nome da ênfase não mais na imanência, mas nos processos, no exercício da linguagem pelo homem. Ora, o foco em Benveniste é a questão da (inter)subjetividade, com o que ele desloca o estudo da imanência para o do uso da língua. Benveniste faz-nos assim o convite a uma travessia: das paisagens do antropológico (homem) às do linguístico (sujeito), imbricadas no ato de enunciar, porém não intercambiáveis na análise e descrição deste (o sujeito é a condição formal, linguística, do homem na linguagem; no entanto, sujeito e homem remetem a duas ordens distintas, o que interdita qualquer interpretação psicologizante, bastante equivocada, dessa noção. $\mathrm{O}$ sujeito em Benveniste não pode ser pensado enquanto qualquer tipo que seja de "substrato pensante"; ele é linguístico). Como bem lembra Normand (2006, p. 19), o eixo central do

\footnotetext{
${ }^{1}$ Dizia-se que trazer à descrição estrutural aquilo que concerne ao sentido, sujeito, situação enunciativa era ceder espaço a aspectos "extralinguísticos" que, como tais, se mostravam impertinentes a uma abordagem estrutural da língua-sistema.
} 
empreendimento benvenistiano é: jamais abandonar a língua, em sua matéria significante, suas estruturas comuns, seu aparelho semiótico, mas fazê-lo de modo a "conciliar esse gesto saussuriano com a singularidade subjetiva, com a comunicação sempre situada, com o 'acontecimento inebriante' que é todo enunciado. Analisar 'o semântico': eis a aposta de Benveniste”. E sobre isso concordamos também com Flores (2005, p. 129), que vê em Benveniste a produção efetiva de "um pensamento absolutamente singular", e com Teixeira (2004a, p. 118), para a qual "ler Benveniste é perceber que atrás da análise pormenorizada da linguagem, encontra-se um ponto de vista filosófico de interesse amplo".

Para Benveniste (2005), o que possibilita a comunicação e mais, a atualização da língua pela enunciação, é a (inter)subjetividade, ou antes, o fato de que é na/pela linguagem que o homem se constitui como sujeito. Ora, sabemos que o homem pode até tentar criar uma língua (esperanto, por exemplo), mas a linguagem ele não inventa, pois ela lhe é inerente, está em sua natureza. Daí a refutação de Benveniste, sobretudo em seu artigo "Da subjetividade na linguagem", à concepção instrumental de linguagem. A linguagem funciona porque um locutor, apresentando-se como sujeito, remete-se como en em seu discurso. Eis a subjetividade de que trata Benveniste (2005): "é 'ego' que dir. ego". O locutor constitui-se em sujeito enunciando eu; e no momento em que o faz, simultaneamente instaura (explícita ou implicitamente) um $t u$, que lhe é não só complementar como reversível, para o qual falará sobre um ele (objeto referido por en e co-referido por $t u$ numa dada instância discursiva). A este $e l e$, o $e u$ e o tu opõem-se por uma correlação de pessoalidade (que permite a referenciação, possibilitando o ato de enunciar sobre algo). Estamos no cerne da releitura que Benveniste (2005) propõe do sistema pronominal e da tradicional classificação de pessoa no verbo: trata-se de pensar e $u$ e $t u$ como pessoa na medida em que, opondo-se entre si por uma correlação de subjetividade (eu é pessoa subjetiva; $t u$, não subjetiva), implicam uma pessoa e um enunciado sobre ela; mas a clássica terceira pessoa, ele, em virtude de poder ser tanto uma infinidade de sujeitos como nenhum (referindo então 
uma coisa), é dita "não pessoa". Na relação eu-tu-ele encontra-se, portanto, o fundamento da intersubjetividade. Isto, porém, não deve sugerir a existência de homogeneidade entre os elementos desta tríade. Como o próprio Benveniste coloca, há aí heterogeneidade (este é, inclusive, um motivo para a releitura em torno da questão da pessoa). Benveniste, segundo Teixeira (2004b, p. 16), "foi um dos raros a empreender uma descrição sistemática do singular dispositivo intralinguístico pelo qual a língua é posta em ato", a saber, o sistema pronominal. Seu estudo - prossegue ela - "associa a reflexão epistemológica ao detalhe das análises empíricas, incidindo sobre questões concretas e insofismáveis".

O exercício da linguagem dá-se por meio da frase, ponte que permite ultrapassar a noção de língua enquanto mero sistema de signos e entrar no campo da língua em uso. A frase é uma unidade de discurso, a "vida da linguagem em ação" (BENVENISTE, 2005, p. 139). Por sua vez, o sentido da frase decorre da referência que ela faz à situação na qual aparece, ou seja, à situação espaço-temporal que lhe dá origem. Vê-se, pois, que pessoa-espaço-tempo são categorias indissociáveis que constroem na enunciação uma tríade essencial: eu-aqui-agora (ou, se considerarmos a inevitável constituição simultânea do outro, constroem um eu-tu-aqui-agora), que se mostra o centro de referência interno da instância de discurso, no interior da qual se deverá pensar o sentido do enunciado. Em "A natureza dos pronomes", Benveniste (2005, p. 277) afirma que cada instância define em seu interior a "realidade de discurso", a referência. Assim, aos signos $e u$ e $t u$, referíveis somente na presente instância que os contém, associam-se outros elementos indiciais, como pronomes demonstrativos, advérbios. Essas formas remetem à enunciação, sempre única, e refletem seu próprio emprego. Trata-se, pois, aqui de "signos vazios" (BENVENISTE, 2005, p. 280): sempre disponíveis, se plenificam apenas quando usados por um locutor, na medida em que este os assume ao enunciar (ele se apropria do aparelho formal da enunciação - ou seja, da língua -, que lhe fornece os signos). Como se pode constatar, nada há de referência às coisas do mundo; logo, a questão dos elementos indiciais é 
concebida, em Benveniste, assim: o sentido de um signo vaæio não existe em virtude da referência feita a uma situação empírica, mas da referência feita àquele que enuncia. Esses signos têm por função promover a comunicação.

Diferentemente de outros sistemas semióticos, a língua, para Benveniste (2006), "é o único sistema em que a significação se articula em duas dimensões", de maneira que o "privilégio da língua" é o de "comportar simultaneamente a significância dos signos e a significância da enunciação". Diz ele: "Daí provém seu poder maior, o de criar um segundo nível de enunciação, em que se torna possível sustentar propósitos significantes sobre a significância" (BENVENISTE, 2006, p. 66). A língua é investida de uma dupla significância, combinando duas ordens que, embora distintas, ocorrem juntas imbricando-se na/pela enunciação, quais sejam: a dimensão semiótica (designando o modo de significação próprio do signo linguístico) e a dimensão semântica (modo de significação engendrado pelo discurso, pelo uso da língua). A primeira deve ser reconhecida, já a segunda, compreendida, pois é precisamente esta, não aquela, que comporta referência.

A língua enquanto sistema disponibiliza um aparelho que permite ao locutor enunciar sua posição de sujeito, e com isto, marca-se este na língua. Nesse sentido, o aparelho formal da enunciação tem um estatuto ao mesmo tempo geral e específico (FLORES et al., 2008): geral, pois todas as línguas o têm; específico, porque é singular para cada língua e é utilizado de modo único pelo sujeito. Passemos, com isso, ao segundo pilar desta reflexão: retomemos que em "O Aparelho Formal da Enunciação" (BENVENISTE, 2006), Benveniste concebe a enunciação como "o fato do locutor que mobiliza a língua por sua conta", ou seja, "é este colocar em funcionamento a língua por um ato individual de utilização" (BENVENISTE, 2006, p. 82), ato por meio do qual se constrói a relação homem-mundo, mediada pela enunciação. Esse ato promove a semantização da língua pela conversão desta em discurso (e que isso não sugira dicotomia, mas conjunção: língua-discurso) e "introduz em primeiro lugar o locutor como parâmetro nas condições necessárias da enunciação" 
(BENVENISTE, 2006, p. 83). Pode-se avançar e dizer que o ato enunciativo, ao ocorrer, entrelaça o eixo semiótico ao semântico, justamente na instância em que o locutor efetua a atualização da língua, já que o aparelho formal apaga no uso a divisão. Assim, a referência passa a ter um estatuto único: a enunciação em sua evanescência e irrepetibilidade.

Ao abordar, em "A linguagem e a experiência humana", as diferentes representações comportadas pelo termo "tempo" (físico, psíquico, crônico etc.) - momento teórico que, segundo Flores (2005), é marcado por uma grande influência de concepções kantianas ${ }^{2}$-, Benveniste (2006) afirma: "é pela língua que se manifesta a experiência humana do tempo". Diz ele, ainda, que a especificidade do tempo linguístico reside no fato de que ele se liga diretamente à enunciação; esse tempo é centrado no presente da instância de discurso. E assim, "cada vez que um locutor emprega a forma gramatical do 'presente' [...], ele situa o acontecimento como contemporâneo da instância do discurso que o menciona" (BENVENISTE, 2006, p. 74-75). Trata-se de um presente reinventado a cada nova enunciação, um tempo axial (do centro eu-aqui-agora), marcando a coincidência entre acontecimento e discurso. Com todo o exposto, tem-se agora um embasamento teórico suficiente para a reflexão que pretendemos fazer através do presente artigo. Certamente, não pretendemos a exaustão (que, aliás, seria impossível no âmbito de um texto desta natureza), e sim uma breve discussão em torno de um tema que nos parece relevante e pouco abordado.

\footnotetext{
${ }^{2}$ Em Kant (1999, p.169), pode-se ler, por exemplo, que o tempo é uma representação e é dado a priori, de modo que "se se quisesse atribuir ao próprio tempo uma sucessão, ter-se-ia que pensar ainda um outro tempo no qual fosse possível tal sucessão". Aqui não faço mais que sintetizar essa questão, já que o tema merece um artigo exclusivo.
} 


\section{A reformulação de livros como ato enunciativo: entre renunciar e reenunciar o dito}

Retomemos que, para Benveniste, a enunciação "é o fato do locutor que mobiliza a língua por sua conta", ou ainda, "é este colocar em funcionamento a língua por um ato individual de utilização" (2006, p. 82), ato por meio do qual se constrói a relação homem-mundo, mediada pela enunciação e somente possível em virtude desta. Trazer isso para a temática deste trabalho permite dizer que é na/pela enunciação que se constitui e explicita (se materializa) a relação autor-livro(s)-leitor. Ora, os fatos e coisas do mundo existem porque são tornados objetos de discurso por/para os homens. Na situação em pauta, temos que ao autor corresponde o locutor (constituído como eu), ao passo que ao leitor corresponde o alocutário (instituído por en como tu), ou seja, pensar autor e leitor é, obrigatoriamente, tomá-los como inscritos no discurso, e não como indivíduos empíricos ("substratos pensantes").

Os livros existem a partir de um trabalho de sintagmatização através do qual a língua se semantiza ao atualizar-se em discurso por meio de um ato enunciativo que, realizando-se pela língua numa situação única, constitui uma cena enunciativa irrepetível, enfim, um eu-tu-aqui-agora singulares. No entanto, o surgimento de novas enunciações - as quais estão diretamente relacionadas a posicionamentos científicos antes inexistentes, a novas concepções que passaram a circular - leva, muitas vezes, à urgência de renunciar o dito e enunciar "novamente" a obra, o que pode ser facilmente constatado através do enunciado a seguir:

\section{(1) $\mathrm{E} 1-\varnothing$}

$\mathrm{E} 2$ - O texto que se segue é bastante diferente do que, escrito em 1967, figurava sob o mesmo titulo [...]. A razão disso é dupla: o campo da Poética não é mais hoje o que era há seis anos e eu próprio não o encaro sempre da mesma maneira. Mas um texto totalmente novo não poderia mais integrar-se em nosso projeto inicial. Preservei, portanto, a intenção geral e o quadro da primeira versão [...], modificando, contudo, o enunciado cada vez que isso 
se tornou necessário para prestar contas do atual estado da Poética. (TODOROV, 1976, p. 7) [grifo nosso]

A partir daí, a consideração benvenistiana quanto à inversibilidade entre as pessoas $e u$-tu permite fundamentar a constatação de que, no processo de reformulação, há uma intrincada rede de relações, quais sejam: latu sensu, tem-se a relação eu-tu-ele, instaurada por um locutor que se dirige a um alocutário; strictu sensu, a conversão daquele $e u$ do locutor ao $t u$ que esse mesmo locutor se torna quando leitor de sua própria obra (afinal, para reformulá-la, ele terá que a ler) e, depois, novamente a condição de $e$, para a produção da edição revista (E2).

O processo de reformulação sinaliza uma espécie de retorno de um ato enunciativo anterior, ato este que, num único movimento, emerge na enunciação em curso e é por ela absorvido, uma vez que passa a subordinar-se ao tempo da instância de discurso atual, enfim, ao presente convocado pelo sujeito enquanto presente do ato enunciativo. Aliás, é a partir do centro interno de referência então vigente que se poderá perceber a não coincidência entre o acontecimento e o discurso referente a ele. Paradoxalmente, a temporalidade evidencia-se em E2 apontando simultaneamente para um movimento de mudança - a retomada e alteração de E1 e para uma permanência, que pretende (apenas pretende) assegurar que, apesar de "outro", ainda é, de certo modo, o "mesmo" livro, situado entre a repetição (sobretudo, do título do livro) e o rearranjo dos elementos linguísticos. Observe-se o seguinte enunciado:

\section{(2) $\mathrm{E} 1-\varnothing$}

E2 - A partir de certa altura de sua jornada, teve este livro o texto estereotipado, e, pois, irrefundível_[...] Mantivemos-lhe, decerto, a fisionomia original com que [a Gramática] fora planejada e redigida, a fim de que se the não deformasse a inteiriça estrutura intelectual e didática; mas, além da correção de um deslize aqui, da atualização de um conceito ali, e, até, da substituição integral de alguns capítulos e acrescimento de outros, enriquecemos copiosamente a exemplificação dos 'fatos' da 
língua, a qual estendemos aos escritores de nossos dias. (ROCHA LIMA, 1972, p. X) [grifo nosso]

Inicialmente, fala-se da trajetória do livro como se ele tivesse sempre sido o mesmo; adiante, são mencionados aspectos que o tornam diferente, o que poderia parecer contraditório à primeira vista. Defendemos, porém, que a formulação a respeito do cuidado em manter a "fisionomia original" com a qual o livro havia sido planejado e redigido, permite afirmar que, no fundo, o sujeito assume um posicionamento segundo o qual não deseja, ou mesmo pensa, que o livro em questão seja outro, distinto daquele que vinha sendo até então. Isto permite ver bem a dissimulação do outro no um, ou seja, do diferente no mesmo. Enfim, retorna aqui a identidade ambígua de que falávamos inicialmente, polêmica também colocada em (1): a questão de saber até que ponto o livro pode (ou não) ser o "mesmo".

A questão agora, para nós, é pensar na atualização da língua, na relação entre a repetibilidade da forma (pois a linguagem seria impossível se a cada instante se inventassem formas novas e únicas) articulada à irrepetibilidade do sentido. Diz Benveniste (2006, p. 231): "a partir da idéia, a cada vez particular, o locutor agencia palavras que neste emprego têm um 'sentido' particular. [...] Se o 'sentido' da frase é a idéia que ela exprime, a 'referência' da frase é o estado de coisas que a provoca". Tais considerações são fundamentais para se pensar, por exemplo, as "ressignificações" em sua relação com a absoluta irrepetibilidade do sentido: ainda que se repita a forma, jamais se terá para ela o mesmo sentido. Quanto a isso, observem-se os enunciados adiante:

(3) E1 - Não somos partidários de pôr epigrafes nem titulos nas diversas partes do trabalho. Contudo, não há inconveniente em colocá-los. (CARRETER; LARA, 1962, p. 67) [grifo nosso]

E2 - Não somos partidários de pôr epigrafes nem titulos nas diversas partes do trabalho. Isto pode prejudicar a unidade da redação. (CARRETER; LARA, 1963, p. 67) [grifo nosso] 
(4) E1 - Acreditamos que a noção de enredo é clara, para todos, pois seu uso é comum quando se faz referência ao 'enredo de um filme ou de um romance'. [...] De agora em diante, vamos chamar assunto ao enredo de um texto. (CARRETER; LARA, 1962, p. 30) [grifos dos autores] E2 - Acreditamos que a noção de assunto é clara, para todos, pois seu uso é comum quando se faz referência ao 'assunto de um filme ou de um romance'. [...] De agora em diante, vamos chamar assunto ao resumo de um texto. (CARRETER; LARA, 1963, p. 30) ${ }^{3}$ [grifos dos autores]

As condições de emprego das formas remetem à concepção de língua enquanto sistema de signos e implicam todo um conjunto de regras sintáticas pelas quais se dá a sintagmatização. Já as condições de emprego da língua, ao implicarem a enunciação, envolvem o ato do sujeito. É no uso da língua (semantização) que um signo, unidade semiótica, deixa de ser virtualidade paradigmática e passa a existir sintagmaticamente como palavra, processo esse no interior do qual se constitui o valor referencial do termo em questão.

Se, de um lado, a repetição de formas atesta a economia enunciativa, segundo a qual não há necessidade de tantos signos quantas forem as enunciações, de outro, a irrepetibilidade da referência afirma a singularidade da enunciação. Em (3), por exemplo, é incontestável que o sentido do enunciado "Não somos partidários de pôr epígrafes nem títulos nas diversas partes do trabalho" é radicalmente distinto em E1 e em E2.

A língua é o único sistema semiótico capaz de comportar metalinguagem, como no caso de (4). Sem pretender exaustão, consultamos um dicionário (SILVEIRA BUENO, 2000) para

\footnotetext{
${ }^{3}$ O item "O 'assunto' do texto", sob o qual figuram as sequências em exame, é homônimo nas duas edições do Manual de Explicação de Textos, de Carreter e Lara, e está presente em página de mesmo número.
} 
conferir os sentidos lexicográficos referentes aos verbetes problematizados em (4):

Enredo: intriga; ardil; mexerico; desenvolvimento de uma peça; escrito literário ou motivo musical. (SILVEIRA BUENO, 2000, p. 296)

Assunto: matéria ou objeto de que se trata; argumento; tema. (SILVEIRA BUENO, 2000, p. 95)

Resumo: ato de resumir; compêndio; compilação; síntese; sinopse; recapitulação. (SILVEIRA BUENO, 2000, p. 678)

Dotados de significação na comunidade dos usuários da língua, os termos "assunto", "resumo", "enredo" (elementos do aparelho formal usados pelo locutor) assumem um valor único a partir das relações que estabelecem com os demais termos. Uma vez linearizados na enunciação, assumem um sentido singular. É neste momento que, mais do que reconhecidos, devem ser compreendidos, co-referidos pelo alocutário, que, na produção da leitura, passará a eu. E assim com tantos quantos forem os alocutários, muitos prestes a enunciar sobre E2 e, então, colocá-la em xeque, podendo até mesmo se constituir uma situação que induza a uma reformulação da edição revista.

\section{O estatuto da edição revista: há efetiva equivalência entre as diferentes edições?}

Avançando, as questões que emergem agora são: até onde é possível e/ou válido ultrapassar os limites da identidade de um livro? Até onde este é ainda o "mesmo"? E até onde ele é efetivamente outro? É disto que trata esta última seção, já que ficou pendente especificar nosso ponto de vista a respeito da polêmica em pauta, o que será feito abaixo.

Em um único ato enunciativo, a edição revista desdobra-se num gesto simultâneo de proximidade e distanciamento quanto à edição anterior: diante disso, o ponto essencial que autoriza a referir o processo discursivo de reformulação de livros enquanto algo 
radicalmente contraditório reside em que não se trata de opor uma edição X à sua edição revista $\mathrm{Y}$, mas de fazer equivaler, como semelhantes de modo geral (ou seja, no "pensamento diretor"), duas edições internamente distintas. Há repetição do título, mas diferença interna (no "corpo do livro"); além disso, como vimos desde um prisma benvenistiano, nem mesmo a repetição de um enunciado deixa de ser uma "reinvenção" da língua.

A identidade polêmica da edição revista é desfeita se se aplica, ao caso que aqui nos mobiliza, a teorização de natureza enunciativa em torno do sentido: ora, tal como uma dada forma a palavra "enredo", por exemplo, tal como aparece em (4) - é passível de significar de modos distintos, assim ocorre também com o título. Tomemos um exemplo: Moderna Gramática Portuguesa, de Bechara. O que significa Moderna em 1987 [ed. original de 1961] quanto às mais recentes pesquisas científicas não pode ser idêntico àquilo que significa Moderna em 2005 [15 reimpressão da edição revista de 1999]. E nessa direção, tampouco Gramática pode significar a mesma coisa diante dos avanços dos estudos linguísticos. A forma, ou seja, o título do livro, permanece materialmente repetida; porém, seu sentido é indubitavelmente outro e, por isso, defendemos que cada edição é singular. É com esses argumentos que justificamos nossa crença em que não há possibilidade de enunciar que os livros sejam efetivamente equivalentes, e sim se pode e se deve pontuar sua irrepetibilidade. Reforça isto o fato de que a cena enunciativa que caracteriza a produção de cada uma das edições é sempre única, portanto, irrepetível.

A ilusão de uma real equivalência entre edições decorre de questões sociais: ora, lembremos que atribuir um nome a alguém ou a algo é engendrar uma possibilidade de singularizar a entidade nomeada, tanto quanto é responder a "o que ou quem é X?"; e, nesse contexto, o nome é jurídico, ao passo que a unidade que ele designa, porém, é não mais do que imaginária. Por trás da repetição aparentemente transparente do título, esconde-se a profunda opacidade do discurso; o confronto entre o saber cuja repetição ainda é autorizada e aquele que deve ser reformulado; o fantasma do outro a espreitar o um. 
Cabe, por fim, resgatar o que afirma, com muita propriedade, Lopes (1997, p. 46): “Certamente, um livro de ciência não vale pelo que ele fixa, mas pelo que ele põe em movimento; não pelo que ele colhe, mas pelo que semeia". E continua, então, o referido autor: "Sabemos todos bem que o futuro é caprichoso e se compraz em entortar hoje o que ontem pareceu correto e em endireitar amanhã o que hoje nossa miopia entorta" (LOPES, 1997). A produção de conhecimento, na medida em que é parte de um processo discursivo mais amplo, existe em constante mutação, prova incontestável de que, antes de qualquer outra coisa, ela envolve o exercício da linguagem pelo homem, enfim, o exercício dessa singular, complexa e fascinante faculdade humana, qual seja, a faculdade de "simbolizar" (BENVENISTE, 2005).

\section{Conclusão}

Buscou-se vislumbrar, pela enunciação, o exercício da linguagem, esta faculdade intrínseca que não cessa de surpreender. A partir daí, chegou-se ao fato de que o processo de revisão coloca em cena a contraditória existência de um mesmo/outro livro, um livro que disfarça sob a forma do "mesmo" título aquele que é referencialmente um outro, de uma nova edição não totalmente re(e)nunciada. O processo aqui examinado revela-se, portanto, uma modalidade de "anulação por acréscimo" (BARTHES, 1984), uma vez que, através de um novo ato enunciativo, tenta anular a edição anterior por meio da produção de uma nova que a ela procure se sobrepor.

A análise feita mostrou enunciações caleidoscópicas, que constroem a cada vez uma cena irrepetível, e revelou, com isso, atos enunciativos que reafirmam o fato de que todo domínio teórico, quaisquer que sejam os métodos e objetos, será sempre (re)construído pela enunciação, pois terá sempre homens falando com outros homens (BENVENISTE, 2005) e buscando, pela inquietude teórica que for - ela sempre implica linguagem -, responder questões que concernem e/ou afetam o próprio homem. Questões procurando, em sua profunda essência, novamente e pela 
primeira vez, apre(e)nder e conceituar a definição mesma de homem pela linguagem.

Cada um dos casos examinados é único, mas, da observação do conjunto, decorrem regularidades, quais sejam: 1) a luta pela constante atualidade do livro e 2) a busca pela inatingível referência ideal; movimento este que, por sua vez, sinaliza, sem cessar, o fato de que nunca se pode dizer tudo (MILNER, 1987), tampouco se pode - para usar aqui um neologismo - "desenunciar" o dito.

Diremos, para concluir, que o sujeito-autor transforma o saber e com isto (re)constrói discursivamente a realidade sobre a qual teoriza; mas há sempre, à espreita, um outro saber, que não cessa de lhe escapar.

\section{Referências}

BARTHES, Roland. O rumor da língua. Lisboa: Edições 70, 1984.

BENVENISTE, Émile. O vocabulário das instituições indoeuropéias. v. I - Economia, Parentesco, Sociedade. Campinas: Unicamp, 1995a.

O vocabulário das instituições indo-européias. v. II Poder, Direito, Religião. Campinas: Unicamp, 1995b.

Problemas de Lingüística Geral I. 5. ed. Campinas: Pontes, 2005.

Problemas de Lingüística Geral II. 2. ed. Campinas: Pontes, 2006.

CULIOLI, Antoine. Théorie du langage et théorie des langues. Pour une linguistique de l'énonciation - Formalisation et opérations de repérages. Tome 2. Paris: Ophrys, 1999. p. 115-123.

DAHLET, Patrick. Dialogização enunciativa e paisagens do sujeito. In: BRAIT, Beth (Org.). Bakhtin, dialogismo e construção do sentido. Campinas: Unicamp, 1997. p. 59-87. 
FLORES, Valdir N. Por que gosto de Benveniste? Desenredo, Passo Fundo, v. 1, n. 2, p. 127-138, jul./dez. 2005.

; SILVA, Silvana; LICHTENBERG, Sônia; WEIGERT, Thaís. Enunciação e gramática. São Paulo: Contexto, 2008.

.; TEIXEIRA, Marlene. Introdução à Lingüística da Enunciação. São Paulo: Contexto, 2005.

KANT, Immanuel. Crítica da razão pura. São Paulo: Nova Cultural, 1999. (Col. Os Pensadores)

LOPES, Edward. A identidade e a diferença - raízes históricas das teorias estruturais da narrativa. São Paulo: EDUSP, 1997.

MILNER, Jean-Claude. O amor da língua. Porto Alegre: Artes Médicas, 1987.

NORMAND, Claudine. Os termos da enunciação em Benveniste. In: OLIVEIRA, Sérgio Lopes; PARLATO, Érika Maria; RABELLO, Silvana (Orgs.). O falar da linguagem. São Paulo: Lovise, 1996. p. 128-152.

Saussure-Benveniste. Letras - Émile Benveniste: interfaces, enunciação \& discursos, Santa Maria, p. 13-21, jul./dez. 2006.

SILVEIRA BUENO, Francisco da. Mini-dicionário da língua portuguesa. rev. e atual. São Paulo: FTD, 2000.

TEIXEIRA, Marlene. Benveniste: um talvez terceiro gesto?. Letras de Hoje, Porto Alegre, v. 39, n. 4, p. 107-120, dez. 2004a. Uma lingüística sobre o que não pôde se dizer: Benveniste.

Correio da APPOA, Porto Alegre, n. 131, p. 12-17, 2004 b. 


\section{Referências do corpus}

BECHARA, Evanildo. Moderna Gramática Portuguesa. 31. ed. São Paulo: Companhia Editora Nacional, 1987.

Moderna Gramática Portuguesa. 37. ed. rev. e ampl. 15. reimpr. Rio de Janeiro: Lucerna, 2005.

CARRETER, Fernando L.; LARA, Cecília de. Manual de explicação de textos - cursos médio e superior. São Paulo: Centro Universitário, 1962.

Manual de explicação de textos - cursos médio e superior. 2. ed. rev. São Paulo: Centro Universitário, 1963.

ROCHA LIMA, Carlos H. Gramática normativa da Língua Portuguesa. 4. ed. Rio de Janeiro: F. Briguiet \& Cia., 1959.

Gramática normativa da Língua Portuguesa. 15. ed. (refundida). Rio de Janeiro: J. Olympio, 1972.

TODOROV, Tzvetan. Estruturalismo e poética. Trad. José P. Paes. São Paulo: Cultrix, 1970.

Estruturalismo e poética. 4. ed. rev. e ampl. cf. ed. franc. de 1973. Trad. José P. Paes; Frederico P. de Barros. São Paulo: Cultrix, 1976. 